\title{
Clinical impact of complement deposition findings on biopsies in acute rejection episodes of pediatric renal transplant patients
} \author{
Mehmet Haberal $^{3}$

\footnotetext{
${ }^{1}$ Department of Pediatric Nephrology, Baskent University Hospital, Ankara, Turkey

${ }^{2}$ Department of Pathology, Baskent University Hospital, Ankara, Turkey

${ }^{3}$ Department of General Surgery, Baskent University Hospital, Ankara, Turkey
}

Kaan Gulleroglu ${ }^{1}$, Esra Baskin ${ }^{1}$, Handan Ozdemir ${ }^{2}$, Aysun C Yilmaz ${ }^{1}$, Ebru Ayvazoglu Soy ${ }^{3}$, Gokhan Moray ${ }^{3}$,

Background: Complement as a part of innate immunity, plays an important role in immune pathologies. Complement C3 activation is related with renal fibrosis. Locally synthetized C3 is more effective than circulating C3 on rejection. C4d staining is accepted as a histological finding of humoral rejection. We evaluate clinical impact of complement deposition findings on biopsies in acute rejection episodes of pediatric renal transplant patients.

Methods: Demographics of the patients, graft functions, infections, acute rejection episodes, and graft loss were recorded from data files of 165 pediatric renal transplant patients. Ninety-eight renal biopsies findings were retrospectively evaluated.

Results: Thirty-three (20 males and 13 females) patients with kidney transplant had different acute rejection episodes (32 cellular acute rejection episodes/12 humoral acute rejection episodes) which proven by biopsy. Mean age of patients with acute rejection episodes at the time of the transplantation was $12.82 \pm 3.87$ years. Mean follow-up time after transplantation was $7.46 \pm 4.79$ years. Glomerular filtration rate (GFR) value at 3 years of follow-up was $64.13 \pm 20.86 \mathrm{~mL} / \mathrm{min}$ and 5 years of follow-up was $41.40 \pm 27.18$ $\mathrm{mL} / \mathrm{min}$. Complement deposition (C1q, C3 and C4 staining) was positive in 22 patients. Twenty-six patients had graft fibrosis. A significant relation between complement deposition and graft fibrosis could not be demonstrated. GFR values were similar at 3 and 5 years of follow-up between patients with and without complement deposition. All patients had a significant decrease in GFR value during follow-up. Patients who had not fibrotic changes in first biopsy had same deterioration of GFR when compared with patient who had fibrotic changes in first biopsy. Graft fibrosis rates were similar for cellular $(78.12 \%)$ and humoral $(75.00 \%)$ acute rejection episodes.

Conclusions: Our data demonstrated that graft outcomes and graft loss after acute rejection episodes cannot be predicted with complement deposition on graft during rejection episode or graft fibrosis. Each patient must be evaluated independently. Future studies can be helpful for determining dependent indicators of graft outcomes.

Corresponding author: Kaan Gulleroglu

E-mail: rectorate@baskent.edu.tr

(c) The Korean Society for Transplantation

This is an Open Access article distributed under the terms of the Creative Commons Attribution Non-Commercial License (http://creativecommons.org/licenses/by-nc/4.0/) which permits unrestricted non-commercial use, distribution, and reproduction in any medium, provided the original work is properly cited. 